STUDI

FRANCESI

\section{Studi Francesi}

Rivista quadrimestrale fondata da Franco Simone

165 (LV | III) | 2011

LA RAPPRESENTAZIONE DELLA MADRE NELLA

LETTERATURA FRANCESE DEL NOVECENTO a cura di Dario Cecchetti e Michele Mastroianni

\title{
Alphonse de Lamartine, Avertissements préfaces et propos sur la poésie et la littérature
}

\author{
Lise Sabourin
}

\section{(2) OpenEdition \\ Journals}

Édition électronique

URL : http://journals.openedition.org/studifrancesi/5051

DOI : 10.4000/studifrancesi.5051

ISSN : 2421-5856

\section{Éditeur}

Rosenberg \& Sellier

\section{Édition imprimée}

Date de publication : 1 décembre 2011

Pagination : 655

ISSN : 0039-2944

\section{Référence électronique}

Lise Sabourin, «Alphonse de Lamartine, Avertissements préfaces et propos sur la poésie et la littérature ». Studi Francesi [En ligne], 165 (LV | III) | 2011, mis en ligne le 30 novembre 2015, consulté le 07 janvier 2021. URL : http://journals.openedition.org/studifrancesi/5051; DOI : https://doi.org/ERREUR PDO dans /localdata/www-bin/Core/Core/Db/Db.class.php L.34 : SQLSTATE[HY000] [2006] MySQL server has gone away

Ce document a été généré automatiquement le 7 janvier 2021.

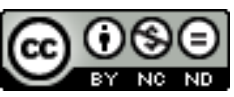

Studi Francesi è distribuita con Licenza Creative Commons Attribuzione - Non commerciale - Non opere derivate 4.0 Internazionale. 


\title{
Alphonse de Lamartine, Avertissements préfaces et propos sur la poésie et la littérature
}

\author{
Lise Sabourin
}

\section{RÉFÉRENCE}

ALPHONSE DE LAMARTINE, Avertissements préfaces et propos sur la poésie et la littérature, textes réunis et présentés par Christian CROISILLE, Paris, Honoré Champion éditeur, «Textes de littérature moderne et contemporaine», 2009, pp. 291.

1 À l'inverse de ses contemporains, notamment Hugo, Lamartine semble considérer les préfaces de ses œuvres comme des formalités plutôt que des lieux propices à exprimer ses théories, allant même jusqu'à déléguer à autrui cet usage éditorial au gré de son libraire. Sans doute faut-il en chercher la raison dans son provincialisme qui le tient à l'écart des querelles du Cénacle et à sa conception «dilettante» de la poésie. Pourtant, conscient $\mathrm{du}$ caractère exceptionnel $\mathrm{du}$ succès des Méditations, il confie aux «avertissements» de ses recueils ultérieurs sa définition de la poésie, surtout après son élection académique, qui lui impose d'exercer son autorité littéraire, a fortiori après son voyage en Orient qui a mûri sa vocation prophétique, manifestée par ailleurs dans son engagement politique. Christian Croisille rassemble dans ce volume tous ces paratextes, ce qui permet d'appréhender d'un coup des écrits souvent éparpillés au fil des éditions et d'en mieux cerner l'évolution.

2 La brièveté des préfaces aux Méditations poétiques de 1820 (pp. 21-24), des Nouvelles Méditations de 1823 (pp. 25-26), de La Mort de Socrate (pp. 27-31) et du Dernier Chant du pèlerinage d'Harold (pp. 33-41) toujours en 1823 trouve ses limites dans celle du Discours de réception à l'Académie d'avril 1830 (pp. 43-48) que Lamartine négligea d'insérer dans ses Euvres complètes. 
3 Mais, après l'avertissement des Harmonies poétiques et religieuses de juin 1830 (pp. 49-51), l'auteur prend conscience de la nécessité de s'expliquer avec plus d'ampleur dans ses Destinées de la poésie de 1834 (pp. 53-89). Jocelyn (1836) (pp. 91-96) lui donne l'occasion de répondre à la polémique par un post-scriptum, redoublé face à la contradiction que suscite La Chute d'un ange en 1838 (pp. 99-115).

4 Désormais, avec les Recueillements poétiques de 1839 (pp. 117-128) et la nouvelle préface de Jocelyn en 1840 (pp.129-136), ou grâce à la justification de son édition des CEuvres choisies en 1849 (pp. 137-164), les textes liminaires prendront un tour plus biographique et personnel, notamment grâce au recours à la lettre-préface, individualisée. C'est le cas de la «Lettre à M. le comte d'Esgrigny» (pp. 165-189) qui accompagne les Harmonies en 1849, avec une tendance vers la démarche mémorialiste pour Les Confidences et Les Nouvelles Confidences en 1849-50 (pp. 191-204 et 205-213). La préface de Geneviève en 1850 (pp. 215-258) correspond plutôt à une lettre ouverte au public.

5 Le volume se clôt par l'ajout de la Biographie d'Homère parue dans «Le Civilisateur» en 1852 (pp. 259-261) et un choix d'extraits du Cours familier de littérature («Qu'est-ce que la poésie» dans le IV Entretien d'avril 1856, pp. 263-275, et «Une page de mémoires. Comment je suis devenu poète», dans le XXIII ${ }^{\mathrm{e}}$ de novembre 1857, pp. 277-283), que le collationneur a jugés utiles d'annexer pour rassembler ainsi tous ces textes où Lamartine parle de la condition poétique. 